\title{
Endlogenous Endophthalmitis: A Five-year Review of Cases at the Raja Perempuan Zainab II Hospital, Kelantan, Malaysia
}

Ngu Dau Bing Michael ${ }^{1}$, Shakiran Gunaseelan ${ }^{1}$, Tengku Norina Tuan Jaffar ${ }^{2}$, Zamri Noordin ${ }^{2}$, Adil Hussein ${ }^{1}$

1. Ophthalmology Department, School of Medical Sciences/Universiti Sains Malaysia, Kelantan, MYS 2. Ophthalmology Department, Raja Perempuan Zainab Il Hospital, Kelantan, MYS

Corresponding author: Ngu Dau Bing Michael, mikeyngu85@yahoo.com

\section{Abstract}

\section{Background}

Endogenous endophthalmitis (EE) is a type of intraocular inflammation secondary to hematogenous spread from a distant infective source within the body and usually occurs in immunocompromised patients.

\section{Objectives}

The aim of this study was to profile the patient characteristics, sources of infection, microbial profiles, and visual outcomes of patients with EE in Raja Perempuan Zainab II Hospital in Kelantan, Malaysia.

\section{Materials and methods}

Data from 18 eyes of 17 patients diagnosed with EE and admitted to the eye ward of Raja Perempuan Zainab II Hospital from January 2012 to December 2016 were retrospectively reviewed. Factors analyzed included patient age, sources of infection, visual acuity, microbial profiles, and treatment outcomes.

\section{Results}

The mean age of the 17 patients was 53.2 years. Twelve patients (70.6\%) had EE of left eye, four (23.5\%) had EE of right eye, and one (5.9\%) had EE involving both the eyes. Sixteen patients (91.1\%) had at least one predisposing condition, the most common of which was diabetes mellitus in 15 patients (88.2\%). A source of infection was identified in 12 of the 17 patients, with urinary tract infection being the most common (five patients, 29.4\%). Organisms were successfully isolated from 10 (58.8\%) patients, including seven (41.2\%) with Gram-negative and three (17.6\%) with Gram-positive organisms. All patients presented with a visual acuity worse than $6 / 60$. Nine (52.9\%) patients underwent vitrectomy, with only two of these patients achieving a final visual acuity better than 6/60. Eleven patients became nonperceptive to light, with four of them undergoing evisceration.

Received 07/06/2018

Review began 07/14/2018 Review ended 07/23/2018 Published 07/30/2018

\section{() Copyright 2018}

Michael et al. This is an open access article distributed under the terms of the Creative Commons Attribution License CC-BY 3.0., which permits unrestricted use, distribution, and reproduction in any medium, provided the original author and source are credited.

\section{Conclusions}

EE is a rare but often devastating ocular condition. Visual outcomes are often poor especially in patients infected with Gram-negative bacteria.

Categories: Internal Medicine, Ophthalmology, Infectious Disease

Keywords: endogenous endophthalmitis, vitrectomy, intravitreal injection, bacteria

\section{Introduction}

Endogenous endophthalmitis (EE) is a fulminant ocular infection resulting in blindness. It is caused by hematogenous spread from a distant infective source within the body and usually occurs in immunocompromised patients or those with prolonged indwelling medical devices. EE is relatively rare, accounting for only two percent to eight percent of patients with endophthalmitis [1].

Under normal circumstances, the blood ocular barrier (BOB) provides a natural resistance against invading organisms. In $\mathrm{EE}$, the $\mathrm{BOB}$ is breached by inflammation, and the microorganisms can penetrate through this barrier into the uveal tract or retinal circulation. This inflammatory process results in the destruction of intraocular tissues [2]. EE is associated with an extremely poor prognosis in most patients. This study aimed to describe the demographic characteristics, microbial profiles, management, and clinical outcomes of patients with EE admitted to Raja Perempuan Zainab II Hospital in Kelantan, Malaysia.

\section{Materials And Methods}




\section{Cureus}

The records of patients diagnosed with EE and managed at Raja Perempuan Zainab II Hospital from January 2012 to December 2016 were retrospectively reviewed. EE was diagnosed based on the presence of lid edema, conjunctival chemosis, corneal haziness, hypopyon, vitritis, and culture sensitivity without an external cause.

Patients with a history of ocular trauma, any ocular surgery within one year of onset, or any evidence of primary external ocular infection were excluded. Demographic characteristics, clinical presentations, microbial profiles, management, and outcomes were obtained from patients' medical records, and data were analyzed using the IBM SPSS Statistics for Windows, Version 22.0 (IBM Corp., Armonk, NY). Data with numerical variables were described as mean and standard deviation, while categorical data were expressed by frequency $(N)$ and percentage. The study protocol was approved by the National Medical Research Register Malaysia and conformed to the Declaration of Helsinki.

\section{Results}

Data from 18 eyes of 17 patients diagnosed with EE, including 16 patients with unilateral involvement and one with bilateral involvement, were retrospectively reviewed (Table 1 ). The 17 patients included seven males (41.2\%) and 10 females (58.8\%) with a mean age $53.2 \pm 13.2$ years at the time of diagnosis (range, 1970 years). Unilateral involvement of the left eye (70.6\%) was more common than the unilateral involvement of the right eye (23.5\%). 


\begin{tabular}{|c|c|c|c|c|c|c|c|c|c|}
\hline Patient & $\begin{array}{l}\text { Sex } \\
\text { (F/M) }\end{array}$ & $\begin{array}{l}\text { Age } \\
\text { (year) }\end{array}$ & Eye & $\begin{array}{l}\text { Medical } \\
\text { comorbidities }\end{array}$ & Isolate & Systemic infection & $\begin{array}{l}\text { Vitrectomy } \\
\text { (Yes/No) }\end{array}$ & Initial VA & Final VA \\
\hline 1 & $\mathrm{~F}$ & 46 & LE & DM, HPT, ESRF & Bacteria & Infected catheter & No & NPL & Evisceration \\
\hline 2 & $\mathrm{~F}$ & 53 & BE & DM, IHD & Bacteria & Pneumonia & Yes & $\begin{array}{l}\text { RE NPL, LE } \\
\text { HM }\end{array}$ & $\begin{array}{l}\text { RE NPL, LE } \\
6 / 18\end{array}$ \\
\hline 3 & M & 64 & RE & DM, HPT & Bacteria & Pneumonia & No & NPL & Evisceration \\
\hline 4 & $\mathrm{~F}$ & 55 & LE & HPT, Asthma & $\begin{array}{l}\text { No } \\
\text { growth }\end{array}$ & Liver abscess & Yes & $1 / 60$ & $6 / 36$ \\
\hline 5 & M & 61 & RE & $\begin{array}{l}\text { DM, HPT, ESRF, } \\
\text { IHD }\end{array}$ & Bacteria & Pyelonephritis & No & HM & Evisceration \\
\hline 6 & $\mathrm{~F}$ & 29 & LE & NIL & Bacteria & Liver abscess & Yes & $\mathrm{PL}$ & NPL \\
\hline 7 & $M$ & 57 & $\mathrm{LE}$ & DM, HPT & Bacteria & Psoas abscess & No & $\mathrm{PL}$ & $\mathrm{NPL}$ \\
\hline 8 & $\mathrm{~F}$ & 67 & LE & DM, HPT & $\begin{array}{l}\text { No } \\
\text { growth }\end{array}$ & Pyelonephritis & No & HM & $6 / 9$ \\
\hline 9 & M & 47 & LE & DM, HPT, CKD & Bacteria & Unknown & No & PL & Evisceration \\
\hline 10 & $\mathrm{~F}$ & 51 & LE & DM & $\begin{array}{l}\text { No } \\
\text { growth }\end{array}$ & Pleural effusion & Yes & $5 / 60$ & NPL \\
\hline 11 & $\mathrm{~F}$ & 19 & LE & DM, ESRF & $\begin{array}{l}\text { No } \\
\text { growth }\end{array}$ & Unknown & Yes & PL & NPL \\
\hline 12 & M & 70 & RE & DM, HPT & Bacteria & Unknown & Yes & PL & NPL \\
\hline 13 & M & 48 & LE & DM, HPT, ESRF & Bacteria & Unknown & Yes & PL & PL \\
\hline 14 & $\mathrm{~F}$ & 59 & LE & DM, HPT & Bacteria & Pyelonephritis & No & HM & HM \\
\hline 15 & $\mathrm{~F}$ & 67 & LE & DM & $\begin{array}{l}\text { No } \\
\text { growth }\end{array}$ & Pyelonephritis & No & HM & HM \\
\hline 16 & M & 52 & RE & DM, HPT, IHD & $\begin{array}{l}\text { No } \\
\text { growth }\end{array}$ & Unknown & Yes & $1 / 60$ & $6 / 24$ \\
\hline 17 & $\mathrm{~F}$ & 59 & LE & DM, HPT & $\begin{array}{l}\text { No } \\
\text { growth }\end{array}$ & $\begin{array}{l}\text { Urinary tract } \\
\text { infection }\end{array}$ & Yes & PL & NPL \\
\hline
\end{tabular}

\section{TABLE 1: Clinical characteristics of patients $(N=17)$.}

Abbreviations: F, female; M, male; LE, left eye; RE, right eye; BE, both eyes; DM, diabetes mellitus; HPT, hypertension; IHD, ischemic heart disease; ESRF, end stage renal failure; CKD, chronic kidney disease; NPL, non-perceptive to light; PL, perceptive to light; HM, hand movement; VA, visual acuity.

Sixteen patients (91.1\%) had at least one factor predisposing to infection, the most common of which was diabetes mellitus in 15 patients (88.2\%). Twelve patients (70.6\%) had an identifiable source of infection, with urinary tract infection (five patients, 29.4\%) being the most common. Other sources of infection included liver abscesses and pneumonia in two patients each (11.8\%), and intravenous catheter, psoas abscess, and pleural effusion in one patient each (5.9\%). However, sources of infection could not be identified in five patients (29.4\%).

Blood or vitreous samples from 10 patients (58.8\%) were culture positive, with seven (41.2\%) yield with Gram-negative and three (17.6\%) with Gram-positive organisms (Table 2). None of these cultures were positive for fungal infection. 


\section{Cureus}

\begin{tabular}{|l|l|}
\hline Organism & $N(\%)$ \\
\hline Culture positive & $10(58.8)$ \\
\hline Culture negative & $7(41.2)$ \\
\hline Gram-positive organisms & \\
\hline Staphylococcus aureus & $2(11.8)$ \\
\hline Enterococcus species & $1(5.9)$ \\
\hline Gram-negative organisms & \\
\hline Klebsiella pneumoniae & $3(17.6)$ \\
\hline Pseudomonas aeroginosa & $3(17.6)$ \\
\hline Enterobacter species & $1(5.9)$ \\
\hline
\end{tabular}

TABLE 2: Microbial isolates from aqueous or vitreous samples $(\mathrm{N}=17)$.

At presentation, all 18 eyes had a visual acuity worse than 6/60. Seven eyes (38.9\%) were perceptive to light, five $(27.8 \%)$ could perceive hand movements, three (16.7\%) were nonperceptive to light, two (11.1\%) had a visual acuity of $1 / 60$, and one (5.6\%) had a visual acuity of 5/60. All patients underwent vitreous tapping with intravitreal antibiotics, as well as being treated with systemic antibiotics once diagnosed. Only the better eye of the patient with bilateral EE was treated with intravitreal antibiotics, whereas the fellow eye was treated conservatively with topical antibiotics due to poor prognosis. Nine patients (nine eyes, $50 \%$ ) underwent vitrectomy. Four patients (four eyes, $22.2 \%$ ) underwent evisceration due to painful blind eye despite intravitreal antibiotics treatment. Eleven eyes of 11 patients (61.1\%) had a final vision of nonperceptive to light, whereas only four eyes (22.2\%) achieved functional visual acuity of $6 / 60$ or better after treatment. Eyes infected with Gram-negative organisms showed no improvement after the treatment compared to eyes infected with Gram-positive organisms or those that were culture negative (Table 3). 


\section{Cureus}

\begin{tabular}{|l|l|}
\hline Organism & $N(\%)$ \\
\hline Gram-positive organisms & $1(5.9)$ \\
\hline Improvement & $1(5.9)$ \\
\hline No change & $0(0)$ \\
Deterioration* & $1(5.9)$ \\
Evisceration & \\
\hline Gram-negative organisms & $0(0)$ \\
\hline Improvement & $1(5.9)$ \\
\hline No change & $3(17.6)$ \\
\hline Deterioration* & $3(17.6)$ \\
Evisceration & \\
\hline Culture negative & $3(17.6)$ \\
\hline Improvement & $1(5.9)$ \\
\hline No change & $3(17.6)$ \\
\hline Deterioration* & $0(0)$ \\
\hline Evisceration & \\
\hline
\end{tabular}

TABLE 3: Visual outcomes based on microbial diagnosis $(N=17)$.

*Excluding evisceration.

\section{Discussion}

Endogenous endophthalmitis is a rare devastating disease, usually occurring in older patients with underlying systemic diseases. The mean age of presentation in our study was 53.2 years, similar to the results of the systemic review, which reported that peak incidence was during the fifth decade of life [1]. A previous systemic review found that the incidence of EE was higher in the right than in left eyes, due to the more proximal and direct arterial blood flow to the right carotid artery [2]. More recent reviews, however, found that the left eye was more commonly affected suggesting that the anatomy of carotid vessels likely had little effect on the site of EE [1, 3-4]. Although many studies have reported a male preponderance [1, 35], our study found that women were more frequently affected.

A systemic review found that $56 \%$ of patients with EE had an underlying medical illness that predisposed to infection, with diabetes mellitus being the commonest [1], and another study reported that all patients with EE had at least one chronic systemic disease [6]. Our findings were similar, in that $88.2 \%$ of our patients had diabetes mellitus. Sources of infection were identified in most of our patients, with urinary tract infection (29.4\%) being the most common. Other sources of infection included liver abscess, pneumonia, and infected intravenous catheter.

Case series from Australia and Germany found a predominance of fungal pathogens in their patients with EE [3, 7-8]. None of the patients in our series, however, were positive for fungal pathogen. Of the 10 patients positive for bacterial infection, seven were infected with Gram-negative and three with Gram-positive organisms. This finding is consistent with studies from Japan and Singapore, which reported that Gramnegative pathogens were the main causative agents of bacterial EE in East Asians [1, 4-5]. We found that three cultures were positive for Klebsiella species and three for Pseudomonas species. A study in an East Asian population found that Klebsiella species were present in almost $90 \%$ of patients with bacterial EE [5]. Moreover, among patients with systemic Klebsiella infection, 7.3\% were found to have EE caused by Klebsiella pneumoniae [9]. Another study found that a liver abscess in the right superior segment positive for K. pneumoniae infection was a significant risk factor for EE [10]. Thus, patients admitted for a liver abscess or systemic K. pneumoniae infection should be monitored closely for endophthalmitis.

Endogenous endophthalmitis generally results in poor functional vision, with prognosis associated with visual acuity at presentation [3-5, 8]. Patients with fungal EE were found to have a better visual prognosis than patients with bacteria EE [7-8]. Among patients with fungal EE, those infected with Candida had better 
outcomes than those infected with Aspergillus, likely because Aspergillus infections result in extensive retinal necrosis and choroidal damage, whereas Candida infections result only in damage to retina foci [11]. Patients infected with Gram-negative organisms usually showed a poorer prognosis than patients infected with Gram-positive organisms [1, 12]. In our series, all three patients with Klebsiella-associated EE who had a final vision of nonperceptive to light despite adequate treatment, showed that Klebsiella infection is rapidly progressive and destructive. None of our patients with Gram-negative EE showed visual improvement after treatment.

Once diagnosed with EE, vitreous tapping should be performed, and intravitreal antibiotics should be administered. Most topical, subconjunctival, and systemic antibiotics do not reach therapeutic levels within the vitreous due to the BOB [13]. This explains why patients can develop EE while on systemic antibiotics for underlying infections. Vancomycin and ceftazidime should be considered first-line intraocular antibiotics for Gram-positive and Gram-negative pathogens, respectively [14]. A 15-year review of patients with culture-positive EE in Queensland, Australia, found that microbes isolated from these patients showed 100\% sensitivity to vancomycin, ceftazidime, and amikacin [15]. In addition to treating these patients with intraocular antibiotics, administration of intravenous antibiotics is also important in the management of EE to treat the underlying source of infection. If the condition does not improve or if the condition deteriorates after medical treatment, surgical intervention such as vitrectomy should be considered. Immediate vitrectomy, however, is not necessary for patients with better than light perception at presentation but may benefit patients with a visual acuity of light perception or worse; that study, however, did not include patients with EE [16]. Patients with EE who underwent vitrectomy, however, were reported to be almost three times more likely to retain useful visual acuity and more than three times less likely to require evisceration or enucleation [1], given that vitrectomy removes endotoxins, exotoxins, and microorganism [14]. All four of our patients who underwent evisceration did not undergo prior vitrectomy.

\section{Conclusions}

Endogenous endophthalmitis is a rare but often devastating ocular condition. Visual outcomes are often poor especially in patients infected with Gram-negative bacteria. A higher index of suspicion should be maintained by physician especially when treating patients with bacteremia.

\section{Additional Information \\ Disclosures}

Human subjects: Consent was obtained by all participants in this study. National Medical Research Register issued approval NMRR-17-444-35047. This retrospective study was registered under National Medical Research Register Malaysia and Malaysia Ministry of Health Medical Research Ethics Committee had approved the study. Animal subjects: All authors have confirmed that this study did not involve animal subjects or tissue. Conflicts of interest: In compliance with the ICMJE uniform disclosure form, all authors declare the following: Payment/services info: All authors have declared that no financial support was received from any organization for the submitted work. Financial relationships: All authors have declared that they have no financial relationships at present or within the previous three years with any organizations that might have an interest in the submitted work. Other relationships: All authors have declared that there are no other relationships or activities that could appear to have influenced the submitted work.

\section{References}

1. Jackson TL, Eykyn SJ, Graham EM, Stanford MR: Endogenous bacterial endophthalmitis: a 17-year prospective series and review of 267 reported cases. Surv Ophthalmol. 2003, 48:403-423. 10.1016/S00396257(03)00054-7

2. Greenwald MJ, Wohl LG, Sell CH: Metastatic bacterial endophthalmitis: a contemporary reappraisal . Surv Ophthalmol. 1986, 31:81-101. 10.1016/0039-6257(86)90076-7

3. Leibovitch I, Lai T, Raymond G, Zadeh R, Nathan F, Selva D: Endogenous endophthalmitis: a 13-year review at a tertiary hospital in South Australia. Scand J Infect Dis. 2005, 37:184-189. 10.1080/00365540410020965

4. Nishida T, Ishida K, Niwa Y, Kawakami H, Mochizuki K, Ohkusu K: An eleven-year retrospective study of endogenous bacterial endophthalmitis. J Ophthalmol. 2015, 10.1155/2015/261310

5. Wong JS, Chan TK, Lee HM, Chee SP: Endogenous bacterial endophthalmitis: an East Asian experience and a reappraisal of a severe ocular affliction. Ophthalmology. 2000, 107:1483-1491. 10.1016/S01616420(00)00216-5

6. Binder MI, Chua J, Kaiser PK, Procop GW, Isada CM: Endogenous endophthalmitis: an 18-year review of culture-positive cases at a tertiary care center. Medicine (Baltimore). 2003, 82:97-105. 10.1097/00005792200303000-00004

7. Connell PP, O'Neill EC, Fabinyi D, et al.: Endogenous endophthalmitis: 10-year experience at a tertiary referral centre. Eye. 2011, 25:66-72. 10.1038/eye.2010.145

8. Ness T, Pelz K, Hansen LL: Endogenous endophthalmitis: microorganisms, disposition and prognosis . Acta Ophthalmol. 2007, 85:852-856. 10.1111/j.1600-0420.2007.00982.x

9. Kashani AH, Eliott D: The emergence of Klebsiella pneumoniae endogenous endophthalmitis in the USA: basic and clinical advances. J Ophthalmic Inflamm Infect. 2013, 3:28. 10.1186/1869-5760-3-28

10. Park IH, Jun CH, Wi JW, et al.: Prevalence of and risk factors for endogenous endophthalmitis in patients 


\section{Cureus}

with pyogenic liver abscesses. Korean J Intern Med. 2015, 30:453-459. 10.3904/kjim.2015.30.4.453

11. Rao NA, Hidayat AA: Endogenous mycotic endophthalmitis: variations in clinical and histopathologic changes in candidiasis compared with aspergillosis. Am J Ophthalmol. 2001, 132:244-251. 10.1016/S00029394(01)00968-0

12. Lee $\mathrm{S}, \mathrm{Um} \mathrm{T}$, Joe SG, et al.: Changes in the clinical features and prognostic factors of endogenous endophthalmitis: fifteen years of clinical experience in Korea. Retina. 2012, 32:977-984. 10.1097/IAE.0b013e318228e312

13. Rubinstein E, Goldfarb J, Keren G, Blumenthal M, Treister G: The penetration of gentamicin into the vitreous humor in man. Invest Ophthalmol Vis Sci. 1983, 24:637-639.

14. Callegan MC, Gilmore MS, Gregory M, et al.: Bacterial endophthalmitis: therapeutic challenges and hostpathogen interactions. Prog Retin Eye Res. 2007, 26:189-203. 10.1016/j.preteyeres.2006.12.001

15. Moloney TP, Park J: Microbiological isolates and antibiotic sensitivities in culture-proven endophthalmitis: a 15-year review. Br J Ophthalmol. 2014, 98:1492-1497. 10.1136/bjophthalmol-2014-305030

16. Endophthalmitis Vitrectomy Study Group: Results of the Endophthalmitis Vitrectomy Study. A randomized trial of immediate vitrectomy and of intravenous antibiotics for the treatment of postoperative bacterial endophthalmitis. Arch Ophthalmol. 1995, 113:1479-1496. 10.1001/archopht.1995.01100120009001 